\title{
The Groningen LCPUFA study: no effect of postnatal long-chain polyunsaturated fatty acids in healthy term infants on neurological condition at 9 years
}

\author{
Corina de Jong ${ }^{1}$, Hedwig K. Kikkert ${ }^{1}$, Vaclav Fidler ${ }^{2}$ and Mijna Hadders-Algra ${ }^{1}$ * \\ ${ }^{1}$ Department of Paediatrics, Institute of Developmental Neurology, University Medical Centre Groningen, Groningen, \\ The Netherlands \\ ${ }^{2}$ Department of Epidemiology, University Medical Centre Groningen, Groningen, The Netherlands
}

(Received 18 September 2009 - Revised 21 January 2010 - Accepted 22 January 2010 - First published online 7 April 2010)

Long-chain PUFA (LCPUFA) supplementation of formula can have beneficial effects on neurodevelopmental outcome in early infancy, but uncertainty exists regarding effects after 6 months. The present study is the first to investigate whether consumption by term infants of formula containing LCPUFA for the first 2 months after birth improves neurological condition of these children at 9 years of age. A prospective, doubleblind, randomised control study was performed in two groups of healthy term infants: a control group with standard formula $(n$ 169) and a LCPUFA-supplemented group (LF; $n$ 146). A breast-fed group (BF; $n$ 159) served as a reference. At age 9 years, children were neurologically assessed according to Touwen, resulting in a Neurological Optimality Score and information on severity and type of minor neurological dysfunction (MND). Information on potential confounders was collected at enrolment and follow-up. Multivariate analyses were carried out to evaluate the effect of nutrition while adjusting for confounders. Attrition $(28 \%)$ was selective: drop-outs in the LF group were more often boys and had a significantly lower mental developmental index at 18 months. Neurological optimality and severity and type of MND at 9 years did not differ between the two formula groups. Children in the BF group showed significantly less often fine manipulative dysfunction than formula-fed children. In conclusion, LCPUFA supplementation of formula during the first 2 postnatal months in healthy term infants does not alter neurological function at school age. The study confirmed that breast-fed infants have a slightly better neurodevelopmental outcome than formula-fed infants.

Long-chain PUFA: Neurodevelopment: Children: Breast-feeding: Groningen LCPUFA study

Long-chain PUFA (LCPUFA) have become a major focus of attention in the field of infant nutrition and development. The Cochrane reviews of the group of Simmer ${ }^{(1,2)}$ indicated that supplementation of formula with LCPUFA, in particular DHA (22:6n-3) and arachidonic acid (20:4n-6), in general does not affect motor, visual and cognitive outcome. However, when the age at which the child is assessed is taken into account the results are less straightforward. Outcome of LCPUFA-supplemented formula groups (especially DHA supplementation) is better in early infancy, but studies which assessed outcome between 6 and 24 months usually did not demonstrate differences between supplemented and non-supplemented groups ${ }^{(1)}$. The latter age period is, however, known for its insensitivity to reveal adverse effects of exposures during early ontogeny ${ }^{(3)}$. Thus, the absence of an effect between 6 and 24 months does not preclude an effect at a later age. Currently data on the effect of LCPUFA supplementation of formula on neurodevelopmental outcome at school age are lacking.

The present study aims at investigating whether consumption by term infants of formula containing LCPUFA for the first 2 months after birth improves the neurological condition of these children at 9 years of age. Neurological development is one of the domains in which the early beneficial effects of LCPUFA manifest themselves. The study is an extension of the original Groningen LCPUFA study, a randomised controlled trial on the effect of supplementation of formula with LCPUFA during the first 2 postnatal months. At the age of 9 years a standardised and age-specific neurological examination was carried out, which specifically assesses minor neurological dysfunction (MND). MND is considered a valid measure of neurological condition that shows a strong relationship with pre- and perinatal adversities ${ }^{(3)}$. Earlier, Lanting et $a l^{(4)}$ reported that breast-feeding was associated with less MND at school age than formula-feeding. The primary outcome measure of the present study was the Neurological Optimality Score (NOS). The NOS uses the optimality concept to summarise neurological condition; it provides a sensitive measure of the child's overall neurological status. Secondary outcome measures were clinical neurological condition in terms of severity and type of MND. Two major forms of MND can be distinguished:

Abbreviations: BF, breast-fed; CF, control with standard formula; IQ, intelligence quotient; LCPUFA, long-chain PUFA; LF, LCPUFA-supplemented; MND, minor neurological dysfunction; NOS, Neurological Optimality Score; OOS, Obstetrical Optimality Score.

* Corresponding author: Dr Mijna Hadders-Algra, fax +31 50 3619158, email m.hadders-algra@med.umcg.nl 
simple and complex MND. Simple MND can be regarded as a typical but non-optimal form of brain function, whereas complex MND is the clinically relevant form of MND.

Based on the literature, we hypothesise that the LCPUFAsupplemented children perform better than the children who received standard formula and that breast-fed children perform better than the formula-fed children. A better performance will be reflected in a higher NOS, less and less severe MND, and a lower prevalence of specific neurological dysfunctions. The effect of sex on relationships between postnatal supplementation and neurological outcome was also determined, as previous studies suggested the possibility of an advantage of LCPUFA supplementation in males ${ }^{(5)}$.

\section{Methods \\ Participants}

Details of the study design have been described previously ${ }^{(6)}$. Mothers of 314 infants chose to bottle-feed their child and 160 opted for breast-feeding. The infants receiving formula were randomised into a standard formula group (control formula, $\mathrm{CF} ; n$ 169) and a LCPUFA-supplemented formula group (LF; $n$ 145). Standard formula consisted of Nutrilon Premium ${ }^{\circledR}$ (Nutricia, Zoetermeer, The Netherlands). For the supplemented formula, the lipid fraction of Nutrilon Premium ${ }^{\circledR}$ was enriched with $0.45 \%$ (by weight) arachidonic acid and $0.30 \%$ (by weight) DHA. The duration of supplementation was 2 months. In case breast-feeding stopped before 2 months, the infant received LCPUFA-supplemented formula until the age of 2 months, and remained in the BF group. All formula-fed infants received control formula between 2 and 6 months. The children underwent neurodevelopmental assessment at 3 and 18 months of age ${ }^{(6,7)}$. Follow-up was achieved in $84 \%\left(3\right.$ months $\left.^{(6)}\right)$ and $92 \%$ (18 months $\left.^{(7)}\right)$ of the original groups. All children seen at the 18 -months follow-up were eligible for re-testing at 9 years. At the 9-year follow-up, both parents and examiners were unaware of the type of formulafeeding the infant had received. The examiners also were blind to the type of milk fed during the first 8 weeks.

\section{Procedures}

Neurological condition of the children was evaluated with the Touwen (1979) examination ${ }^{(8)}$, which is a standardised, agespecific assessment designed for the assessment of MND. Essential in the diagnostics of MND is the presence of coherent clusters of signs. Single signs do not have clinical significance; signs only have significance when they cooccur (cluster) with other signs within a functional domain. The examination is organised into eight functional domains: posture and muscle tone; reflexes; dyskinesia; coordination; fine manipulative ability; associated movements; sensory deficits; cranial nerve functioning. The examination results in a clinical classification: normal; simple MND; complex MND; or abnormal. A child is considered neurologically abnormal in the presence of a clear neurological disorder such as cerebral palsy. Simple MND denotes the presence of one or two domains of dysfunction and is present in about $15-20 \%$ of children. It has little clinical relevance and can be regarded as typical but non-optimal brain functioning, in other words as a minor neurological difference. Complex MND denotes the presence of more than two domains of dysfunction and is the clinically relevant form of MND. In an aetiological sense it can be considered a borderline form of cerebral palsy as it is linked to a chain of pre- and perinatal adversities ${ }^{(3,9)}$. A child is classified as neurologically normal when no domains are scored as deviant or in case of the isolated presence of a mild dysfunction in reflex activity.

The neurological examination according to Touwen ${ }^{(8)}$ has a good intra-rater, inter-rater and test-retest reliability; the $\kappa$ statistics of the three forms of reliability for neurological classification ranged between 0.71 and $0.83^{(9)}$. Its construct validity is reflected by the differential relationship for simple and complex MND with prenatal and perinatal adversities: adverse conditions during early life have a weak to moderate relationship with simple MND and a strong correlation with complex $\mathrm{MND}^{(3,10)}$. Predictive validity is good; this is reflected by the relationship between the severity of MND at 9 years and the risk of MND at 12 and 14 years and that of learning and behavioural problems at 9 and 14 years $^{(3,11,12)}$.

The study's primary outcome parameter was the NOS. The NOS uses the optimality concept to summarise neurological condition and provides a sensitive measure of the child's overall neurological status. The sensitivity of the NOS to detect effects of early nutrition may be illustrated by the study of Bouwstra et $a l .{ }^{(13)}$ which demonstrated that prenatal fatty acid status was related to NOS at 18 months, but not to outcome measured with the Bayley Scales of Infant Development. For sixty-four items, representing the entire neurological examination, an optimal range was identified (see online Supplemental Table 1). The total number of items with a value within the predefined optimal range formed the NOS of a child. It should be realised that there is a conceptual difference between normality and optimality, as the range for optimal behaviour is narrower than that of normal behaviour $^{(14)}$. The NOS may be regarded as a quantitative and more subtle expression of the clinical neurological condition. This also means that the two measures are highly correlated ${ }^{(15)}$ (present study $\rho=-0.691 ; P<0.001$ ). The quantitative and precise nature of the NOS makes it a suitable instrument to evaluate subtle deviations in neurodevelopmental outcome. The NOS has previously been used in infancy and pre-school-age children; in the present study NOS principles are applied for the first time at the age of 9 years.

Data on prenatal and perinatal conditions had been collected during enrolment with the help of the Obstetrical Optimality Score (OOS). The OOS describes the obstetrical conditions ranging from the parents' socio-economic status to the infant's condition immediately after birth ${ }^{(15)}$. At the 18-months assessment, maternal verbal intelligence quotient (IQ) was estimated using a very abbreviated version of the Wechsler Adult Intelligence Scale, WAIS III, limited to the subtests information and vocabulary ${ }^{(16)}$. Social condition was documented with the Home Observation for Measurement of the Environment (HOME) inventory ${ }^{(17)}$. The HOME contains forty-five items clustered into six subscales: Parental Responsivity; Acceptance of Child; Organization of the Environment; Learning Materials; Parental Involvement; Variety in Experience. At the 9-year follow-up information was collected on parental education and profession, the child's medical history, family composition and nutritional habits. 
Table 1. Obstetrical and social characteristics of the three groups assessed at 9 years

\begin{tabular}{|c|c|c|c|c|c|c|c|}
\hline \multirow[b]{2}{*}{ Variable } & \multicolumn{2}{|c|}{ BF group ( $n$ 127) } & \multicolumn{2}{|c|}{ LF group $(n 91)$} & \multicolumn{3}{|c|}{ CF group ( $n$ 123) } \\
\hline & $n$ & $\%$ & $n$ & $\%$ & $n$ & & $\%$ \\
\hline Retention (\% of original study groups) & & 79 & & 63 & & & 73 \\
\hline \multicolumn{8}{|l|}{ Sex } \\
\hline Boys & 64 & & 42 & & 71 & & \\
\hline Girls & 63 & & 49 & & 52 & & \\
\hline \multicolumn{8}{|l|}{ Duration of second stage of delivery ( $\mathrm{min}$ ) } \\
\hline Median & \multicolumn{2}{|c|}{25} & \multicolumn{2}{|c|}{22} & \multicolumn{3}{|c|}{22} \\
\hline Range & \multicolumn{2}{|c|}{$2-138$} & \multicolumn{2}{|c|}{$1-120$} & \multicolumn{3}{|c|}{$1-146$} \\
\hline \multicolumn{8}{|l|}{ Birth weight $(\mathrm{g})$} \\
\hline Mean & \multicolumn{2}{|c|}{3588} & \multicolumn{2}{|c|}{3527} & \multicolumn{3}{|c|}{3518} \\
\hline SD & \multicolumn{2}{|c|}{436} & \multicolumn{2}{|c|}{498} & \multicolumn{3}{|c|}{473} \\
\hline \multicolumn{8}{|l|}{ Apgar score $3 \mathrm{~min}$ after birth } \\
\hline Median & \multirow{2}{*}{\multicolumn{2}{|c|}{$\begin{array}{c}10 \\
5-10\end{array}$}} & \multirow{2}{*}{\multicolumn{2}{|c|}{$\begin{array}{c}10 \\
7-10\end{array}$}} & \multirow{2}{*}{\multicolumn{3}{|c|}{$\begin{array}{c}10 \\
7-10\end{array}$}} \\
\hline Range & & & & & & & \\
\hline \multicolumn{8}{|l|}{ Maternal education* } \\
\hline High (university education or vocational college) & 60 & 49 & 13 & 15 & 15 & & 13 \\
\hline Medium (college graduate or junior vocational college) & 57 & 46 & 52 & 60 & 85 & & 72 \\
\hline Low (no education or primary education) & 6 & 5 & 22 & 25 & 18 & & 15 \\
\hline Presence of maternal smoking during pregnancy & 25 & 20 & 31 & 34 & 44 & & 36 \\
\hline Presence of maternal hypertension during pregnancy & 11 & 9 & 11 & 12 & 21 & & 17 \\
\hline HOME & & & & & & & \\
\hline Median & \multicolumn{2}{|c|}{44} & \multicolumn{2}{|c|}{43} & \multicolumn{3}{|c|}{43} \\
\hline Range & \multicolumn{2}{|c|}{$39-45$} & \multicolumn{2}{|c|}{$32-45$} & \multicolumn{3}{|c|}{$35-45$} \\
\hline \multicolumn{8}{|l|}{ oos } \\
\hline Median & \multirow{2}{*}{\multicolumn{2}{|c|}{$\begin{array}{c}60 \\
43-69\end{array}$}} & & & & 59 & \\
\hline Range & & & & & & $49-67$ & \\
\hline
\end{tabular}

BF, breast-fed; LF, long-chain PUFA-supplemented formula-fed; CF, control formula-fed; HOME, Home Observation for the Measurement of the Environment inventory; OOS, Obstetrical Optimality Score.

* Significant difference between all groups $(P=0.001)$.

† Significant difference between BF and LF/CF combined $(P=0.003)$.

Depending on the wish of the participants, the assessment was carried out in the hospital or at home. The present study was conducted according to the guidelines laid down in the Declaration of Helsinki and all procedures involving human subjects were approved by the Ethics Committee of the Groningen University Hospital. Written informed consent was obtained from all subjects. The trial is registered under ISRCTN52788665.

\section{Statistical analysis}

Statistical analysis focused on differences in neurological outcome between the two randomised formula groups. In addition, differences between the breast-fed group and the formula groups were analysed. Specific attention was paid to the effect of site of investigation and maternal estimated verbal IQ. Neurological classification, specific clusters of dysfunction and NOS were not normally distributed. Univariate analyses were performed with the Mann-Whitney $U$ test and the Kruskall-Wallis test.

In order to analyse the effect of nutritional group on neurological classification and type of dysfunction while taking into account the role of potential confounders, logistic regression analyses were performed. The following confounders, associated with neurological outcome at $P<0 \cdot 20$, were entered into the analyses: sex; maternal smoking during pregnancy; duration of the second stage of delivery; birth weight; OOS; maternal hypertension during pregnancy; Apgar score $3 \mathrm{~min}$ after birth; maternal educational level. To investigate the effect of nutritional group and the above-mentioned confounders on NOS, multiple linear regression was applied to the NOS transformed to the fifth power. This transformation to normality was identified by the Box-Cox method applied to regression model residuals (the NOS was skewed to the left).

The multivariate analyses on the effect of nutritional group were carried out in two steps. In the first analysis the effect of the type of formula was assessed; in the second analysis the difference between formula- and breast-feeding was evaluated. $P \leq 0.05$ was considered statistically significant. Statistical analyses were performed using SPSS 14.0 for Windows (SPSS, Inc., Chicago, IL, USA).

\section{Results}

All children who were tested at 18 months were invited for follow-up at 9 years ( $n$ 436); 341 of the 474 children of the original study agreed to participate, ninety-one children in the LF group (63\%), 123 children in the CF group (73\%) and 127 children in the BF group (79\%; Fig. 1). Obstetrical data of the study groups and sociodemographic characteristics of the parents are described in Table 1. In general, obstetrical and social characteristics of the children who were and who were not assessed at 9 years were comparable. Yet, children who were not assessed at 9 years had shown significantly more often normal-optimal general movements at 3 months than those who had been assessed, meaning that children with an optimal neuromotor condition in early infancy were under-represented in the follow-up of the three groups at 9 years $(P=0.003)$. In addition, attrition in the LF group 
Healthy term infants enrolled at birth $(n$ 474)

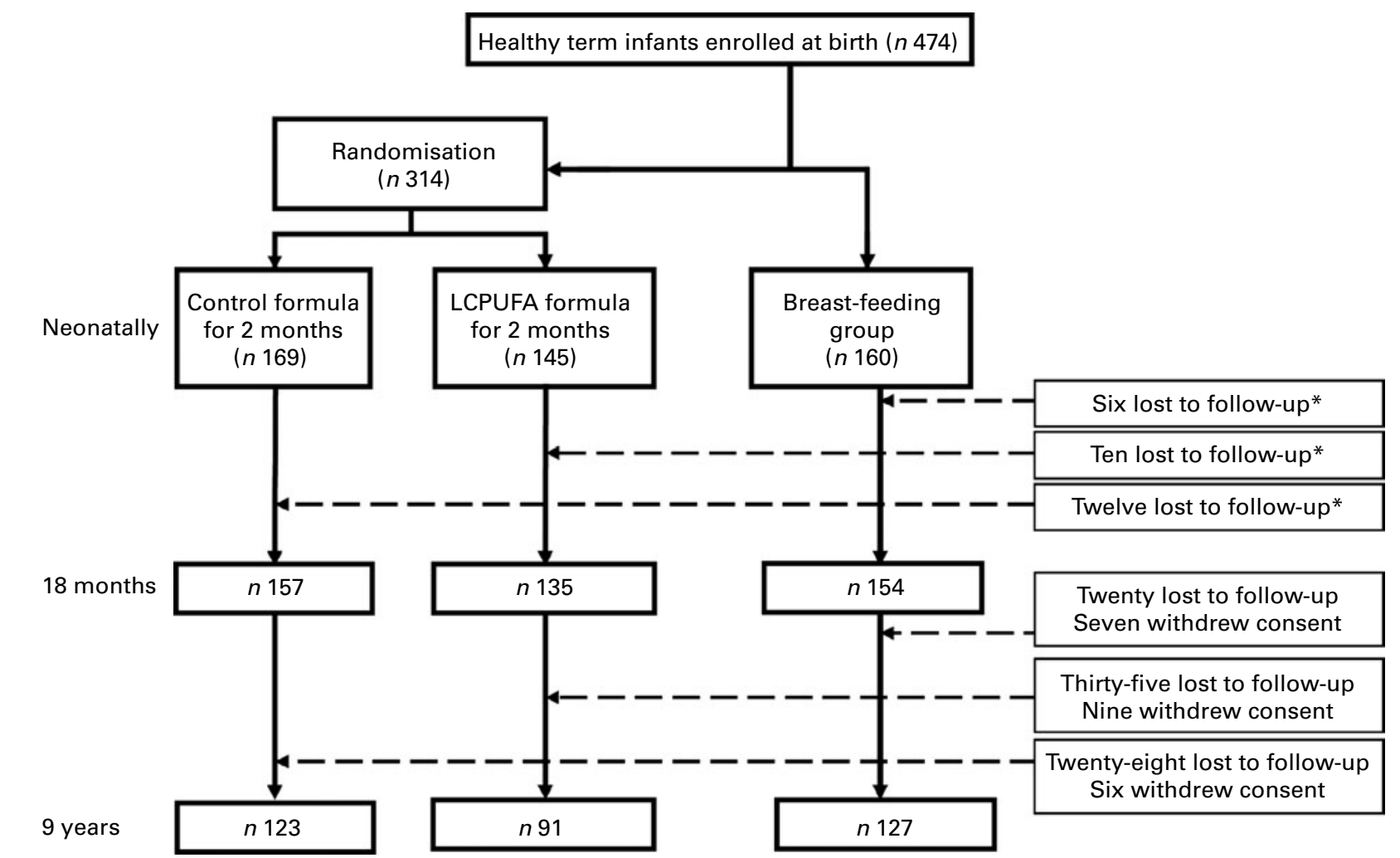

Fig. 1. Flow diagram of children enrolled in the study and followed up until 9 years of age. * for more detailed information, see Bouwstra et al. ${ }^{(7)}$. LCPUFA, long-chain PUFA.

was more selective than in the other groups. First, in the LF group more boys did not take part in the follow-up (thirty-five boys and seventeen girls) compared with the BF group (fifteen boys and seventeen girls) and the $\mathrm{CF}$ group (twenty-four boys and seventeen girls). Second, the mental developmental index of the Bayley Scales of Infant Development ${ }^{(18,19)}$ at 18 months of the children of the LF group who were not assessed at 9 years was significantly lower than that of LF children who did participate in the follow-up at 9 years $(P=0.007)$. A similar selective attrition was not present in the $\mathrm{CF}$ and $\mathrm{BF}$ groups.

Neurological condition at 9 years was not affected by the site of investigation (in the hospital or at home), by current consumption of fish (dichotomised as at least once per week or less than once per week) and maternal verbal IQ. The NOS of children in the LF and CF groups did not differ; in both groups the median NOS score was 57 . The NOS of formula-fed children ( $\mathrm{LF}$ and $\mathrm{CF}$ groups) was significantly lower than that of breast-fed children (median values 57 and 58, respectively, Mann-Whitney, $P=0.008$; see also Table 2 for more specifics on the $\mathrm{BF}$ group). Multiple regression (Table 3) confirmed that the NOS was not affected by LCPUFA supplementation. The analysis revealed an interaction between sex and type of feeding: girls who had been breast-fed had a higher NOS than girls who had been formula-fed. Other factors associated with a higher NOS were higher birth weight and an OOS above the 10th percentile. The effects presented in Table 3 are on the transformed scale of NOS. An effect of size, for example, 0.4 on the transformed scale can be interpreted on the original scale as follows. A NOS value of 57 transforms to $(57 / 50)^{5}=1.9254$; increasing this by 0.4 gives 2.3254 ; transforming this back to the original scale gives $50 \times 2 \cdot 3254^{0.2}=59 \cdot 2$. Note that as the width of most confidence intervals in Table 3 is below $0 \cdot 4$, the $\mathrm{CI}$ width thus becomes about 2 points on the original NOS scale. The NOS at 9 years showed a statistically significant association with the mental developmental index of the Bayley Scales of Infant Development at 18 months (Spearman $\rho=0 \cdot 193 ; P<0 \cdot 0001$ ).

Of the children, 46 to $54 \%$ had a normal neurological condition, 36-39\% showed simple MND and 10-15\% of children had complex MND. Neurological classification did not differ between the randomised formula groups. Children in the BF group tended to have a slightly better neurological condition than the children in the formula-fed groups, but the difference did not reach statistical significance $(P=0 \cdot 17$; Table 4).

LF and CF groups did not differ in the prevalence of specific types of dysfunction. Children of the BF group, however, showed significantly less often fine manipulative

Table 2. Duration of exclusive breast-feeding and Neurological Optimality Score

\begin{tabular}{lccc}
\hline $\begin{array}{l}\text { Duration of exclusive } \\
\text { breast-feeding... }\end{array}$ & $3-5$ weeks & $6-8$ weeks & $>8$ weeks \\
\hline $\begin{array}{l}\text { Children }(n) \\
\text { Neurological } \\
\text { Optimality Score }\end{array}$ & 25 & 23 & 62 \\
$\quad \begin{array}{l}\text { Median } \\
\text { Range }\end{array}$ & 58 & 58 & 58 \\
\hline
\end{tabular}


Table 3. Results of linear regression analysis of factors contributing to the normalised Neurological Optimality Score (NOS): $(\mathrm{NOS} / 50)^{5 *}$

\begin{tabular}{|c|c|c|c|}
\hline Variables & Effect & $95 \% \mathrm{Cl}$ & $P$ \\
\hline \multicolumn{4}{|l|}{ Type of feeding by sex } \\
\hline \multicolumn{4}{|l|}{ Males } \\
\hline LF v. CF (reference) & 0.173 & $-0.055,0.401$ & 0.137 \\
\hline $\mathrm{BF} v \cdot \mathrm{CF}$ & 0.141 & $-0.057,0.340$ & 0.162 \\
\hline BF $v$. LF & -0.031 & $-0.261,0.198$ & 0.788 \\
\hline \multicolumn{4}{|l|}{ Females } \\
\hline LF $v$. CF & -0.100 & $-0.328,0.128$ & 0.389 \\
\hline $\mathrm{BF} v \cdot \mathrm{CF}$ & 0.238 & $0.024,0.452$ & 0.029 \\
\hline BF $v$. LF & 0.338 & $0.122,0.555$ & 0.002 \\
\hline \multicolumn{4}{|l|}{ Sex by type of feeding } \\
\hline CF female $v$. male & 0.367 & $0.156,0.578$ & 0.001 \\
\hline BF female $v$. male & 0.464 & $0.262,0.665$ & 0.001 \\
\hline LF female $v$. male & 0.094 & $-0.150,0.338$ & 0.450 \\
\hline Birth weight (kg) & 0.147 & $0.012,0.282$ & 0.032 \\
\hline $\begin{array}{l}\text { OOS: above } v \text {. below } \\
\text { the } 10 \text { th percentile }\end{array}$ & 0.211 & $-0.021,0.443$ & 0.075 \\
\hline
\end{tabular}

LF, long-chain PUFA-supplemented formula-fed group; CF, control formula-fed group; BF, breast-fed group; OOS, Obstetrical Optimality Score.

${ }^{*} n$ 330; $R^{2} 0.14$; intercept for a CF male with birth weight $3.5 \mathrm{~kg}$ and OOS above 10th percentile, $1 \cdot 7265$.

dysfunction than formula-fed children (BF $16 \%$, LF $30 \%$, $\mathrm{CF} 31 \%$; $\mathrm{BF} v$. formula groups; $P=0.002)$. This was confirmed in multivariate analysis (Table 5) with the following contributing factors: OOS below the 10th percentile; male sex; maternal smoking during pregnancy; duration of the second stage of delivery. Breast-fed and formula-fed children did not differ in the prevalence of other types of neurological dysfunction.

\section{Discussion}

The present study indicated that consumption by term infants of formula containing LCPUFA for the first 2 months after birth did not affect neurological condition at 9 years. The study also revealed that fine manipulative ability of breastfed children was better than that of formula-fed children.

A major limitation of the study is its attrition. Overall attrition was $28 \%$, which - over a period of 9 years - can be regarded as relatively favourable ${ }^{(20)}$. However, a major problem in the present study was the selective nature of attrition, that is, a selective loss of boys and children with a worse cognitive development at 18 months in the LF group. The

Table 4. Neurological classification by nutritional group* (Number of children and percentages)

\begin{tabular}{|c|c|c|c|c|c|c|}
\hline & \multicolumn{2}{|c|}{$\begin{array}{l}\text { BF group } \\
(n \text { 127) }\end{array}$} & \multicolumn{2}{|c|}{$\begin{array}{l}\text { LF group } \\
\quad(n 91)\end{array}$} & \multicolumn{2}{|c|}{$\begin{array}{c}\text { CF group } \\
(n 123)\end{array}$} \\
\hline & $n$ & $\%$ & $n$ & $\%$ & $n$ & $\%$ \\
\hline Neurologically normal & 68 & 54 & 44 & 48 & 56 & 46 \\
\hline Simple MND & 46 & 36 & 35 & 39 & 48 & 39 \\
\hline Complex MND & 13 & 10 & 12 & 13 & 19 & 15 \\
\hline
\end{tabular}

BF, breast-fed; LF, long-chain PUFA-supplemented formula-fed; CF, control formula-fed; MND, minor neurological dysfunction.

* No statistically significant differences were present between the groups.
Table 5. Results of logistic regression analysis of factors contributing to fine manipulative dysfunction (explained variance of $18.5 \%$ )

(Odds ratios and $95 \%$ confidence intervals)

\begin{tabular}{llll}
\hline Contributing factors & OR & $95 \% \mathrm{Cl}$ & $P$ \\
\hline Type of feeding & & & \\
BF (reference) & 1 & & \\
LF & $2 \cdot 668$ & $1.3,5 \cdot 7$ & 0.011 \\
CF & 2.548 & $1.3,5 \cdot 2$ & 0.009 \\
Covariates & $2 \cdot 151$ & $1.2,3.9$ & 0.010 \\
$\quad$ Male sex & $7 \cdot 271$ & $2.3,23$ & 0.001 \\
OOS below the 10th percentile & 1.935 & $1.1,3.6$ & 0.034 \\
Maternal smoking & 0.989 & $0.98,1$ & 0.032 \\
Duration of 2nd part of delivery & & & \\
\hline BF, breast-feeding; LF, long-chain PUFA-supplemented formula-feeding; CF, &
\end{tabular}

selective attrition interfered with the randomised design of the study. While the multiple regression analysis can alleviate the effect of attrition if the missingness of data depends only on known covariates, it cannot annihilate the effect of severe ('missing not at random') attrition.

Some of the breast-fed children received a few weeks of formula supplemented with LCPUFA (Table 2). This may be considered a limitation, as it may have influenced any differences between the supplemented formula group and the breast-fed group. However, the finding that the neurological condition of the LF group did not differ from the CF group reduces the likelihood that differences between the LF and $\mathrm{BF}$ groups were affected by the mixed composition of the BF group.

The prevalence of MND in the present study is another point which deserves methodological attention. The prevalence is higher than indicated by earlier estimations of MND in the general population ${ }^{(3)}$. This may raise questions regarding the representativeness of the current sample of healthy full-term infants. However, neurological evaluation of these groups at 3 months indicated that neurological status was representative for the general population ${ }^{(6,21)}$. Possibly, the relatively high prevalence of MND in the present study reflects the general trend of worsening neuromotor condition in the last decades ${ }^{(22)}$.

The strengths of the study are its randomised design and its assessor-blinded evaluation with an internationally recognised, sensitive technique to evaluate neurological condition ${ }^{(4,23-26)}$. Based on the width of the confidence intervals, it is concluded that the LF $v$. CF differences do not exceed 2.2 points on the NOS scale.

This is the first study reporting the effect of supplementation of formula with LCPUFA in healthy term infants on neurological condition at school age. Using the NOS, a sensitive indicator of neurological condition, an effect of 2 months of postnatal LCPUFA supplementation on neurological status at 9 years could not be demonstrated. Bearing in mind the fact that the LF group suffered from selective attrition of children with a lower mental developmental index at 18 months, the present study indicates that LCPUFA supplementation during the first 2 postnatal months does not promote neurological condition at school age.

The present finding of a subtle positive association between breast-feeding and neurodevelopmental outcome, 
and neurological condition in particular, is in line with reports of others ${ }^{(4,27,28)}$. The association between breast-feeding and neurological outcome was less strong than previously reported by Lanting et al. ${ }^{(4)}$, which may be attributed to differences in the populations studied (Lanting et al. study: a mix of highrisk and low-risk infants; present study: healthy full-term infants) and the quality of the breast-feeding data (Lanting et al. study: retrospectively collected information; present study: detailed prospective information). Der et al. ${ }^{(29)}$ were able to demonstrate that maternal IQ accounted for a major part of the association between breast-feeding and developmental outcome in terms of IQ. In the present study, a subtle association between breast-feeding and fine manipulative ability remained, also when estimated maternal verbal IQ was taken into account. Fine manipulative ability is mediated especially by cortical-subcortical networks. These networks do not only play a role in sensorimotor aspects of motor programming, movement planning, program selection and motor memory but also in cognitive functions, such as intelligence $^{(30,31)}$. This means that the association between breast-feeding and better fine manipulative ability corresponds to reports of others of an association between breast-feeding and higher $\mathrm{IQ}^{(27)}$. Interestingly, the NOS data indicated that especially girls profit from the beneficial effect of breast-feeding. This sex-specific effect may be explained by shared genome, and, albeit less likely, sex-specific differences in metabolism of $\alpha$-linolenic acid: adult women have a higher conversion rate of $\alpha$-linolenic acid to EPA and DHA than adult men ${ }^{(32)}$.

In conclusion, the present study indicates that LCPUFA supplementation of formula during the first 2 postnatal months in healthy term infants does not promote neurological condition at school age. In addition, the study confirmed that breast-fed infants have a slightly better neurodevelopmental outcome than formula-fed infants - reflected in the present study by a reduced prevalence of fine manipulative dysfunction. Finally, the study underscores the need of the evaluation of selective attrition with respect to early developmental data in studies assessing the effect of early nutrition on long-term developmental outcome.

\section{Acknowledgements}

We gratefully acknowledge the critical comments of Dr G. Boehm on a previous draft of the paper.

Previous parts of the LCPUFA study have been funded by Numico Research B.V. The follow-up at 9 years is part of the Early Nutrition Programming Project (EARNEST), which is funded under the Food Quality and Safety Priority of the Sixth Framework Programme for Research and Technical Development of the European Community (FOOD-CT-2005-007036; www.metabolic-programming.org).

M. H.-A. initiated the follow-up study; C. de J. and H. K. K. collected the data; C. de J., V. F. and M. H.-A. analysed the data; C. de J. and M. H.-A. drafted the report; H. K. K. and V. F. commented on drafts. All authors have seen and approved the final version.

There are no conflicts of interest.

Supplemental Table 1 is available online only at http:// journals.cambridge.org/action/displayJournal?jid=bjn

\section{References}

1. Simmer K, Patole SK \& Rao SC (2008) Longchain polyunsaturated fatty acid supplementation in infants born at term. The Cochrane Database of Systematic Reviews 2008, issue 1, CD000376. http://www.mrw.interscience.wiley.com/cochrane/ clsysrev/articles/CD000376/frame.html

2. Simmer K, Schulzke SM \& Patole SK (2008) Longchain polyunsaturated fatty acid supplementation in preterm infants. The Cochrane Database of Systematic Reviews 2008, issue 1, CD000375. http://www.mrw.interscience.wiley.com/cochrane/ clsysrev/articles/CD000375/frame.html

3. Hadders-Algra M (2002) Two distinct forms of minor neurological dysfunction: perspectives emerging from a review of data of the Groningen Perinatal Project. Dev Med Child Neurol 44, 561-571.

4. Lanting CI, Fidler V, Huisman M, et al. (1994) Neurological differences between 9-year-old children fed breast-milk or formula-milk as babies. Lancet 344, 1319-1322.

5. Hadders-Algra M, Bouwstra H, van Goor SA, et al. (2007) Prenatal and early postnatal fatty acid status and neurodevelopmental outcome. J Perinat Med 35, s25-s28.

6. Bouwstra H, Dijck-Brouwer DAJ, Wildeman JAL, et al. (2003) Long-chain polyunsaturated fatty acids have a positive effect on the quality of general movements of healthy term infants. Am J Clin Nutr 78, 313-318.

7. Bouwstra H, Dijck-Brouwer DA, Boehm G, et al. (2005) Long-chain polyunsaturated fatty acids and neurological developmental outcome at 18 months in healthy term infants. Acta Paediatr 94, 26-32.

8. Touwen BCL (1979) Examination of the Child with Minor Neurological Dysfunction. Clinics in Developmental Medicine, no. 71. London: Heinemann Medical Books.

9. Peters LH, Maathuis KGB, Kouw E, et al. (2008) Test-retest, inter-assessor and intra-assessor reliability of the modified Touwen examination. Eur J Paediatr Neurol 12, 328-333.

10. Hadders-Algra M, Huisjes HJ \& Touwen BCL (1988) Perinatal correlates of major and minor neurological dysfunction at school age: a multivariate analysis. Dev Med Child Neurol 30, $472-481$

11. Soorani-Lunsing RJ, Hadders-Algra $\mathrm{M}$, Olinga $\mathrm{A}$, et al. (1993) Is minor neurological dysfunction at 12 years related to behaviour and cognition? Dev Med Child Neurol 35, 321-330.

12. Soorani-Lunsing RJ, Hadders-Algra M, Huisjes HJ, et al. (1993) Minor neurological dysfunction after the onset of puberty: association with perinatal events. Early Hum Dev 33, 71-80.

13. Bouwstra H, Dijck-Brouwer J, Decsi T, et al. (2006) Neurologic condition of healthy term infants at 18 months: positive association with venous umbilical DHA status and negative association with umbilical trans-fatty acids. Pediatr Res 60, 334-339.

14. Prechtl HF (1980) The optimality concept. Early Hum Dev 4, 201-205.

15. Touwen BCL, Huisjes HJ, Jurgens-Van der Zee AD, et al. (1980) Obstetrical condition and neonatal neurological morbidity. An analysis with the help of the optimality concept. Early Hum Dev 4, 207-228.

16. Wechsler D (2000) WAIS-III Nederlandstalige Bewerking. Technische Handleiding (WAIS-III Dutch Version. Technical Manual). Lisse, The Netherlands: Swets \& Zeitlinger.

17. Caldwell B \& Bradley R (1984) Home Observation for Measurement of the Environment. Little Rock, AR: University of Arkansas at Little Rock.

18. Bayley N (1993) Bayley Scales of Infant Development, Second Edition: Manual. San Antonio, TX: The Psychological Corporation. 
19. van der Meulen B, Ruiter S, Lutje Spelberg H, et al. (2002) BSID-II-NL Dutch Manual. Lisse, The Netherlands: Swets Test Publishers.

20. Fewtrell MS, Kennedy K, Singhal A, et al. (2008) How much loss to follow-up is acceptable in long-term randomised trials and prospective studies? Arch Dis Child 93, 458-461.

21. Bouwstra H, Dijk-Stigter GR, Grooten HMJ, et al. (2009) Prevalence of abnormal general movements in threemonth-old infants. Early Hum Dev 85, 399-403.

22. Hadders-Algra M (2007) Atypical performance: how do we deal with that? Dev Med Child Neurol 49, 403.

23. Barnett A (2002) Neurological and perceptual-motor outcome at 5-6 years of age in children with neonatal encephalopathy: relationship with neonatal brain MRI. Neuropediatrics 33, 242

24. Mikkola K, Ritari N, Tommiska V, et al. (2005) Neurodevelopmental outcome at 5 years of age of a national cohort of extremely low birth weight infants who were born in 1996 1997. Pediatrics 116, 1391-1400.

25. Schmolck H, Maritz E, Kletzin I, et al. (2005) Neurologic, neuropsychologic, and electroencephalographic findings after European tick-borne encephalitis in children. $J$ Child Neurol 20, $500-508$
26. Arnaud C, Daubisse-Marliac L, White-Koning M, et al. (2007) Prevalence and associated factors of minor neuromotor dysfunctions at age 5 years in prematurely born children: the EPIPAGE Study. Arch Pediatr Adolesc Med 161, $1053-1061$

27. Anderson JW, Johnstone BM \& Remley DT (1999) Breastfeeding and cognitive development: a meta-analysis. Am $J$ Clin Nutr 70, 525-535.

28. Lanting CI, Patandin S, Weisglas-Kuperus N, et al. (1998) Breastfeeding and neurological outcome at 42 months. Acta Paediatr 87, 1224-1229.

29. Der G, Batty GD \& Deary IJ (2006) Effect of breast feeding on intelligence in children: prospective study, sibling pairs analysis, and meta-analysis. BMJ 333, 945-948

30. Alexander GE \& Crutcher MD (1990) Functional architecture of basal ganglia circuits - neural substrates of parallel processing. Trends Neurosci 13, 266-271.

31. Diamond A (2000) Close interrelation of motor development and cognitive development and of the cerebellum and prefrontal cortex. Child Dev 71, 44-56.

32. Burdge GC (2006) Metabolism of $\alpha$-linolenic acid in humans. PLEFA 75, 161-168. 